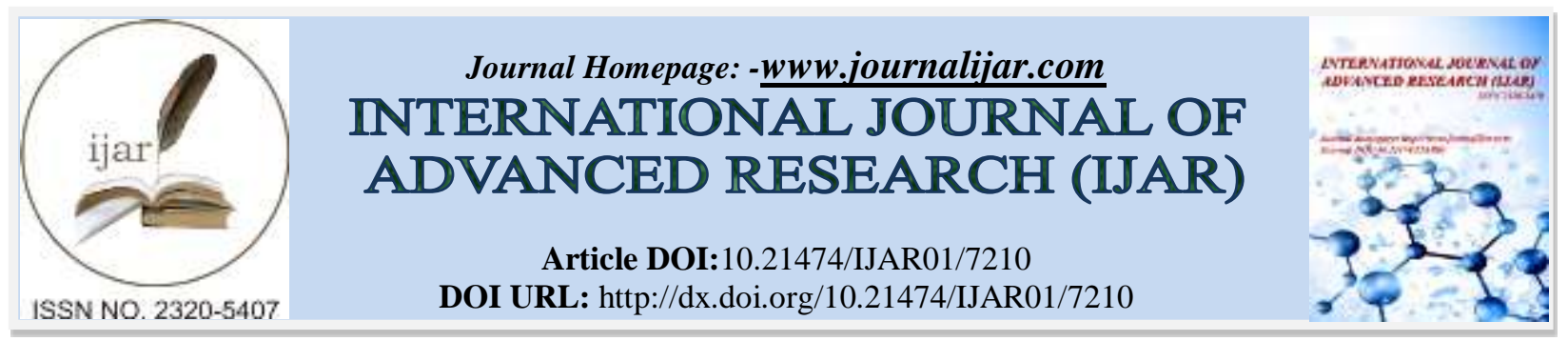

RESEARCH ARTICLE

\title{
PERCEPTION OF SMALLHOLDER FARMERS' ON CLIMATE CHANGE AND VARIABILITY IN DIRE DAWA ADMINISTRATION.
}

\author{
Betelhem abebe. \\ Department of Geography and Environmental Studies, Mizan-Tepi University, Ethiopia.
}

\section{Manuscript Info}

Manuscript History

Received: 05 April 2018

Final Accepted: 07 May 2018

Published: June 2018

Keywords:-

Adaptation, Climate change/variability, Perception.

\section{Abstract}

This study was aimed to assess perception of smallholder farmers' on climate change and variability and its impact in two rural kebeles of Dire Dawa Administration. Both primary and secondary data sources were used and data's were analyzed qualitatively and quantitatively.

The result obtained from meteorological data and respondents perception on local climate change and variability is almost indicates an increase in temperature and variability in rainfall. Local people also perceived the prevalence of hazards affecting their livelihood such as drought, extreme heat, livestock disease and flood. Changing planting date, implementing soil and water conservation techniques, shifting from cattle to goats and sheep, income source diversification and sowing drought tolerant crops are the major adaptation options employed by the farmers. The farmers also identifies lack of money, lack of information, shortage of land, poor potential for irrigation, lack of market access, lack of credit access, lack of agricultural inputs and lack of extension service as most important barriers to adaptation. Improving farmers' skill and knowledge through training, providing them with credit access and improved agricultural inputs, increasing their involvement in small scale irrigation and water harvesting should be done to elevate farmers' adaptive capacity to the change in local climate.

Copy Right, IJAR, 2018,. All rights reserved.

\section{Introduction:-}

Agriculture is the most important sector in most developing countries particularly in sub-Saharan Africa (SSA). It employs More than $60 \%$ of active population and contributes, on average, $40 \%$ of GDPs of the region. Negative impacts of climate change on agriculture in SSA are likely to be highly significant (Kandji et al., 2006).

IPCC (2007) predict that areas of the sub-Sahara are likely to emerge as the most vulnerable to climate change by 2100 with likely agricultural losses of between 2 and 7\% of countries GDP (Ibid). Western and Central Africa are expected to have losses ranging from 2 to $4 \%$ and Northern and Southern Africa are expected to have losses of 0.4 to $1.3 \%$ (Mendelsohn et al., 2000).

Like other sub-Saharan countries, agriculture is the base of Ethiopian economy. It comprises about $43 \%$ of national GDP, generates $90 \%$ of foreign exchange earnings and employs more than $80 \%$ of the population. It is also the major source of food for the population and the prime contributing sector to food security. In addition, agriculture is 
expected to play a key role in generating surplus capital to speed up the country's overall socio-economic development (CSA, 2008). However, productivity and competitiveness of this sector is increasingly constrained by temporal and spatial variability of climate.

Ethiopian agriculture is one of the most vulnerable sectors to current climatic variability and projected climate change, potentially exposing millions of people to recurrent food shortages and episodic famines. Negative impact of climate change and variability on crop and livestock production could result in a nationwide food shortage and greatly hinder the economy (Assfa et al., 2008). For instance, droughts in Ethiopia can shrink household farm production by up to $90 \%$ of normal years output and could lead to the death of livestock and human beings (World Bank, 2003).

Long term trends towards reduced rainfall and recurring droughts have played a role in weakening of the Ethiopian economy (USAID, 2004) and it continues to be a major challenge for the Ethiopian community (United Nation, 2008). In the twenty-first century there has been a rising frequency of extreme droughts due to global warming in Ethiopia (IDS, 2008). The country has faced sharp droughts at least twice per decade. For the last five to seven decades, with the most serious ones in 1972-73, 1984 and 2002-03 (Mideksa, 2010).

Current climate variability is already imposing a significant challenge to Ethiopia by affecting food security, water and energy supply, poverty reduction and sustainable development efforts, as well as by causing natural resource degradation and natural disasters (Abebe, 2007).

In Dire Dawa most of the rural people live in drought prone areas and are vulnerable to the impacts of drought. According to disaster vulnerability assessment report of Disaster Prevention and Food Security office of DDA (DPFSO, 2012), more than 48,275 people in rural Dire Dawa were identified to be chronically food insecure and another 60,000 peoples were highly affected in bad production years. Since the year 2000, a series of food shortage because of prolonged drought induced crop loss has been registered in Dire Dawa. And currently there is a minimum of three month food gap in Dire Dawa.

The decline in amount of rain fall, erratic nature of the rain and even the failure of the main or short rainy seasons or uneven rainfall distribution, aggravated by climate change, is creating serious water shortage and stress particularly on the rural households (DDAEPA, 2011).

However, it is possible to reduce adverse effects of climate change and variability by formulating effective and efficient adaptation strategies. Adaptation to climate change/variability refers to adjustment in natural or human systems in response to actual or expected climatic stimuli or their effects, which moderates harm or exploits beneficial opportunities (IPCC, 2001).

Adaptation to climate change requires that farmers first notice the climate is changing, and then identify useful adaptation measures to cope with the problems and implement them effectively and efficiently (Temesgen, 2007). With regard to this, farmers' perception to climate change and variability, and their efforts to adapt and cope with the impact of climate change and variability in Dire Dawa were not well studied.

Yet in Ethiopia, there are some research outputs concerning adaptation to climate change and variability. Temesgen et al. (2009), Temesgen et al. (2011) and Falco et al. (2011) studied perception and adaptation process in the Nile Basin of Ethiopia. Yibekal et al (2013) studied the process of adaptation to climate change by smallholder farmer in east Hararghe zone of oromiya and Bryan et al. (2009) compared the adaptation process in Ethiopia with other African countries. However, Jeffcott (2013) studied the adaptation strategy of farmers to climate change and variability in eastern Ethiopia; Aemro et al (2012) studied climate change adaptation strategy of smallholder farmers in Babile district, east Hararghe Zone. Studies carried out so far are limited to some part of the country.

The aim of this study was to analyze the perception of smallholding farmers to climate change and/variability in Dire Dawa Administration (DDA). The specific objectives were to: i) Assess farmers' perceptions of changes/variability in the local climate, ii) Identify the impact of climate change/variability induced hazards on local peoples and iii) Identify adaptation measures employed by farmers in response to any changes and /variability in local climate. 


\section{Description Of The Study Area And Research Methodology:- Description of the study area:-}

Geographically, Dire Dawa Administration (DDA) is located in eastern part of Ethiopia. Total area coverage of the administration is about 128,802 ha. DDA is characterized by two agro ecological zones. The topographic feature of the administration is range from 960 m.a.s.l in north east and up to 2450 m.a.s.l in south west. As a result of this narrow altitudinal variation $1500 \mathrm{~m}$ is serving as line of separation between Kolla AEZ (below 1500m) and Woyina Dega (above 1500m) (DDAEPA, 2011).

The Administration is characterized by an arid and semi-arid climate with low and erratic rainfall. The administration has a bimodal type of rainfall with April as a peak for the small and August for big rain seasons. The rainfall pattern is characterized by small rain in spring and big rain in summer with June as a dry spell. The rainy season is from February to May and from July to September but, from these seven rainy months only rainfall of July and August exceeds half the potential evapo-transpiration. From October to January is dry season.

Figure 1:-Average monthly rainfall, max and min. temperature at DDA

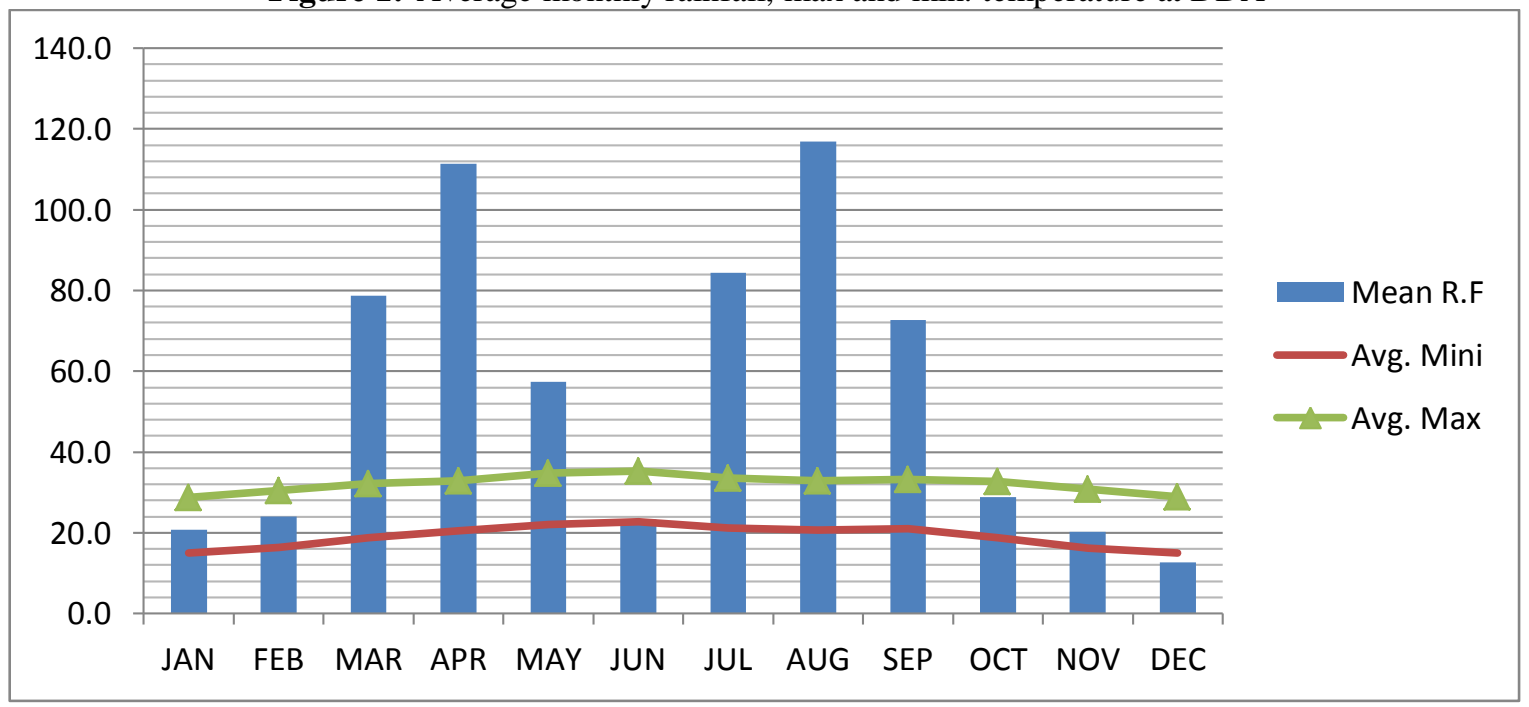

Source: NMA, 2014 (drown by the author)

Mixed farming is the major economic activity in the rural area of the Administration (96\%). Although a variety of crops do grow in the administration, sorghum is the only crop, which grows under rain-fed conditions. The low and variable rainfall and drought resistant property of the crop are the main reasons for this. In the mountain foot slopes, valley bottoms and river terraces a variety of crops both annuals and perennials do grow under both rain- fed and irrigated conditions. The cereal crops grown in the DDA are sorghum and maize only. Besides the cereal crops, a variety of vegetables such as onion, tomato, pepper and cabbages, cash crops such as chat and coffee and fruits like papaya and banana are also grown. The remaining $4 \%$ of the rural population are pure pastoralists, engaged in livestock production (DDAEPA, 2011).

\section{Research methodology:-}

\section{Sampling technique and size:-}

For this study the researcher was employed both purposive and random sampling technique for selecting study area and sampled households, respectively. There are 38 rural kebeles in DDA out of those kebeles two kebeles were selected from different agro-ecological zone (micro-climate variations). Accordingly, the selected kebeles were Legeoda Mirga from Kolla zone and Legeoda Gudinfeta from Woina Dega zone.

This study used a simplified formula provided by (Yamane, 1967 cited in Mesfin, 2006) to determine the required sample size at $95 \%$ confidence level, degree of variability $=0.5$ and level of precision $=9 \%(0.09)$

$$
n=\frac{N}{1+N(e)^{2}}
$$


Where $\mathrm{n}$ is the sample size, $\mathrm{N}$ is the population size (total household heads size), and e is the level of precision. The above formula requires a minimum of 118 sampled households as the total household number of the 2 rural kebeles is 2451 .

This study covered 120 households, proportionally to their total number of households in each kebeles. Accordingly, 61 and 59 households were sampled for household survey from Legeoda Mirga and Legeoda Gudinfeta kebeles, randomly.

Data sources and method of collection:-

In order to achieve the objective of the study and ensure the reliability and validity of collected data both primary and secondary data sources were employed. Primary data were generated from three types of data sources. These were: household survey as a major data source and complemented by FGDs and field observation. Secondary data was collected from official documents and records of methodological data and other published and unpublished literatures.

For household survey, structured questionnaire were prepared focusing on major research issues such as, perception of farmers towards trend of changes and variability in local climate, adaptation strategies of farmers to climate change and variability and key constraints they faced to adopt different strategies. The major discussion topics on FGD were local communities understanding of climate change and variability and its impact, major hazards and their impacts and indigenous adaptation measures employed by them.

\section{Method of data analysis:-}

The data obtained from primary and secondary data sources were analyzed by using both qualitative and quantitative method of data analysis.

The qualitative information gathered through focus group discussions was analyzed by using qualitative technique. Whereas the quantitative data obtained from questionnaire and meteorological data were analyzed by using descriptive statistics (mean, frequency, percentage, standard deviation and count).

Comparison between farmers' perception of climate change and variability and 30 years rainfall and temperature data (1984-2013) was made by undertaking linear trend analysis. Coefficient of variation and percent of deviation were used to determine rainfall variability. EXCEL 2007 software was used as a tool for the analysis.

Data Analysis And Discussion:-

Characteristics of sample households;-

Table 1:-Sex composition, age and educational status of households in the study area

\begin{tabular}{|c|c|c|c|c|c|}
\hline \multirow{2}{*}{\multicolumn{2}{|c|}{ Variables }} & \multicolumn{2}{|c|}{ Kebeles } & \multirow{3}{*}{$\begin{array}{c}\text { Total } \\
13 \\
\end{array}$} & \multirow{3}{*}{$\begin{array}{c}\text { Percent } \\
10.8\end{array}$} \\
\hline & & \multirow{2}{*}{$\begin{array}{c}\text { Legeoda } \\
\text { Gunufeta } \\
8\end{array}$} & \multirow{2}{*}{$\begin{array}{c}\text { Legeoda Mirga } \\
5\end{array}$} & & \\
\hline \multirow{2}{*}{ Sex of HHH } & Female & & & & \\
\hline & Male & 51 & 56 & 107 & 89.2 \\
\hline Total & & 59 & 61 & 120 & 100 \\
\hline \multirow[t]{5}{*}{ Educational status } & Unable to read & 36 & 44 & 80 & 66.7 \\
\hline & and write & 13 & 13 & 26 & 21.7 \\
\hline & Grade 1-4 & 9 & 4 & 13 & 10.9 \\
\hline & Grade 5-10 & 1 & 0 & 1 & 0.8 \\
\hline & $10+3$ & 59 & 61 & 120 & 100 \\
\hline \multicolumn{6}{|l|}{ Total } \\
\hline & & Minimum & Maximum & Mean & Std. Deviation \\
\hline Age of $\mathrm{HHH}$ & & 20 & 68 & 36.9 & 8.6 \\
\hline
\end{tabular}

Source: Filed survey, 2014 
Total households included in this study were 120, of which $89.2 \%$ (42.5\% from Legeoda Gunufeta and 46.7\% from Legeoda Mirga Kebele) and 10.8\% (6.7\% from Legeoda Gunufeta and 4.1\% from Legeoda Mirga Kebele) were male and female headed households, respectively

Age distribution of respondents ranged from 20-68 years for Legeoda Gunufeta and 25-60 years for Legeoda Mirga, and the average age of households was 37. However, about 67 (46\%) of respondents were below the average.

The result of household survey shows that, educational status of household heads was considerably low. More than half $(66.7 \%)$ of respondents were unable to read and write. This determines readiness of households to accept new ideas and technologies to cope with climatic hazards.

\section{Annual and seasonal rainfall trend and variability;- Annual rainfall trend:-}

Annual rainfall of the study area ranged between $357 \mathrm{~mm}$ and $666 \mathrm{~mm}$. Figure 2, shows inter-annual variability of annual rainfall over the last 30 years. The inter-annual distribution of rainfall showed that annual amounts were below the average $(639.7 \mathrm{~mm})$ for most years. The analysis of linear trend showed that the amount of annual rainfall remained more or less unchanged between 1984 and 2013.

Figure 2:-Annual rainfall trend and variability at DDA (1984-2013)

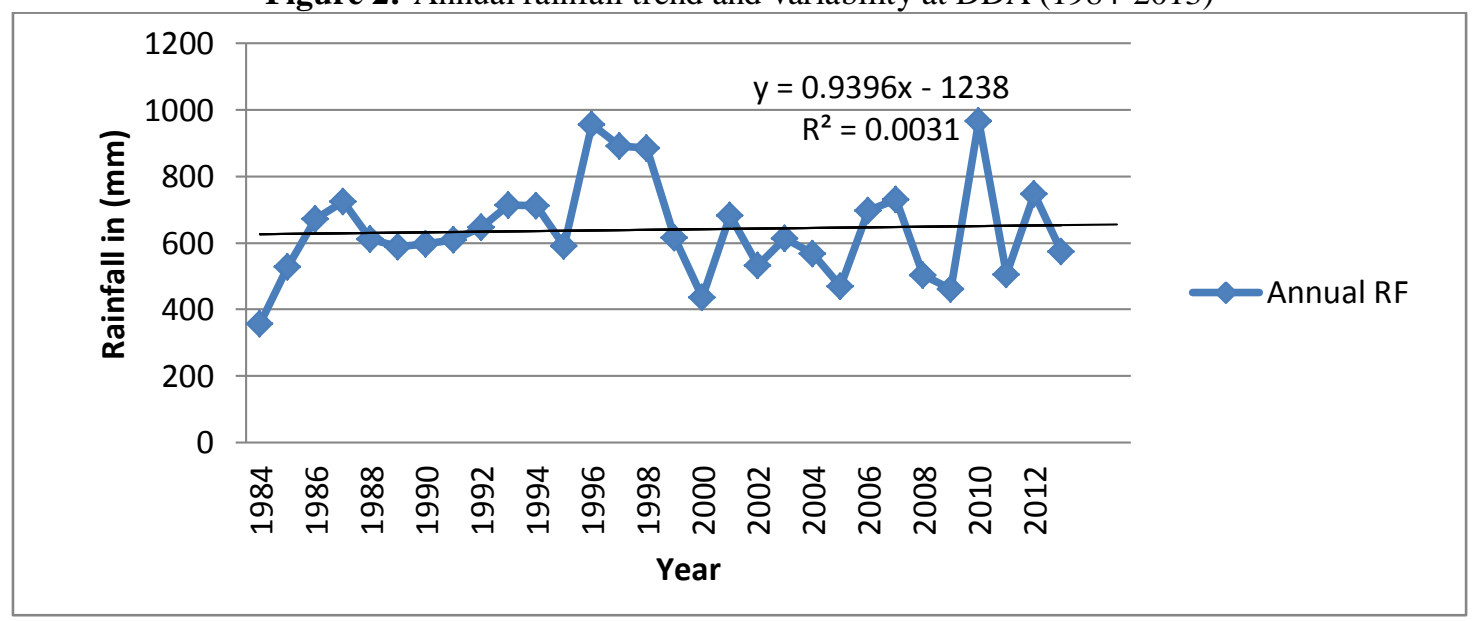

Source: NMA, 2014 (drawn by the author)

\section{Seasonal rainfall trends and variability:-}

There was high inter-annual variability in the amount of belg and kiremt rainfall. Rainfall of belg season has shown (figure 3) decline trend from1984-2013. It has decreased by $5.19 \mathrm{~mm}$ per year over the past three decades. On the other hand kiremt rain has shown (figure 4) an increasing trend, its amount increased by $4.07 \mathrm{~mm}$ per year in the period noted above. 
Figure 3:-Belg rainfall trend and variability at DDA (1984-2013)

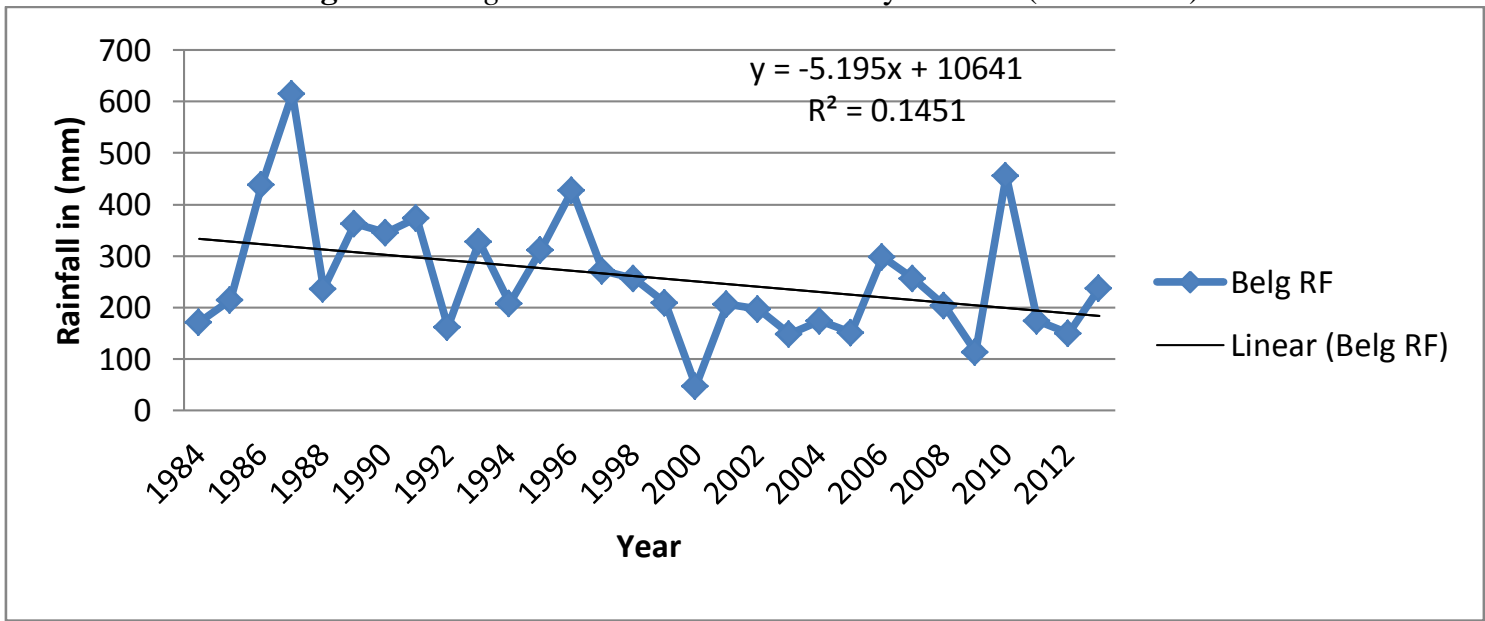

Source: NMA, 2014 (drawn by the author)

Figure 4:-Kiremt rainfall trend and variability at DDA (1984-2013)

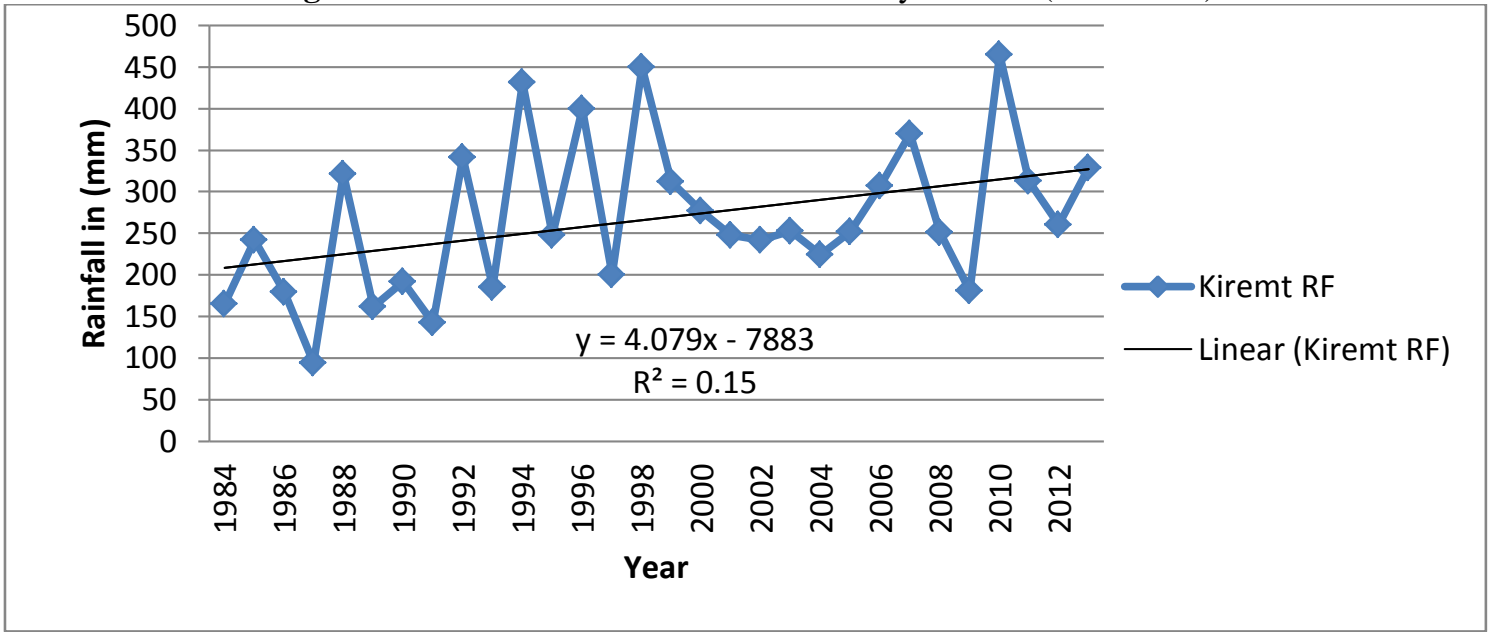

Source: NMA, 2014 (drawn by the author)

As it is shown in Table 2, coefficients of variations were 23\%, 46\% and 35\% for annual, belg and kiremt rainfall, respectively; which indicate that there was high inter-annual variability of rainfall between 1984 and 2013. Degree of variation in amount of rainfall was higher for belg season than kiremt season.

Table 2:-Coefficient of variance total annual, belg and kiremt R.F at DDA (1984-2013)

\begin{tabular}{|l|c|c|}
\hline Rainfall & Mean rainfall $(\mathrm{mm})$ & CV $(\%)$ \\
\hline Annual & 639.7 & 23 \\
\hline Belg & 258.5 & 46 \\
\hline Kiremt & 267.9 & 35 \\
\hline
\end{tabular}

Source: Computed from the data obtained from NMA, 2014

According to the National Meteorological Agency of Ethiopia (NMA, 2010), drought occur when the negative anomaly from the mean seasonal rainfall is $19 \%$ or more. Further droughts are classified as moderate and sever if the seasonal rainfall deficiency is between $21 \%$ to $25 \%$, and more than $25 \%$, respectively.

Based on that criterion of NMA, the area has experienced significant number of drought years in the period between 1984 and 2013. 13 annual severe droughts occurred in the stated period. And 15 and 8 severe droughts occurred in belg and kiremt seasons. Among the 13 annual severe droughts, 8 of them occurred after 2000 and among the 15 severe droughts which occurred in belg season 11 of them happened after 1999. This indicates that, since 2000 G.C. 
the number of drought victims receiving food aid was increased due to decline of agricultural production especially; crop production resulted from agricultural drought.

Additionally, disaster preparedness and food security office of DDA (2012) reported that, there was 83,081.52 quintal food gap and 36,925.12 rural people needed food aid in 2012/2013 production year. This was due to the occurrence of drought; there was $46.12 \%$ and $36.5 \%$ food gap in the same production year in Legeoda Gunufeta and Legeoda mirga, respectively.

Even though, there was high seasonal variability of rain fall, drought is not a silent feature of the area. Because, the gradual trend shows drought is not a normal cycle in the area.

Figure 5:-Standardized anomaly of total annual, belg and kiremt R.F at DDA (1984 - 2013)

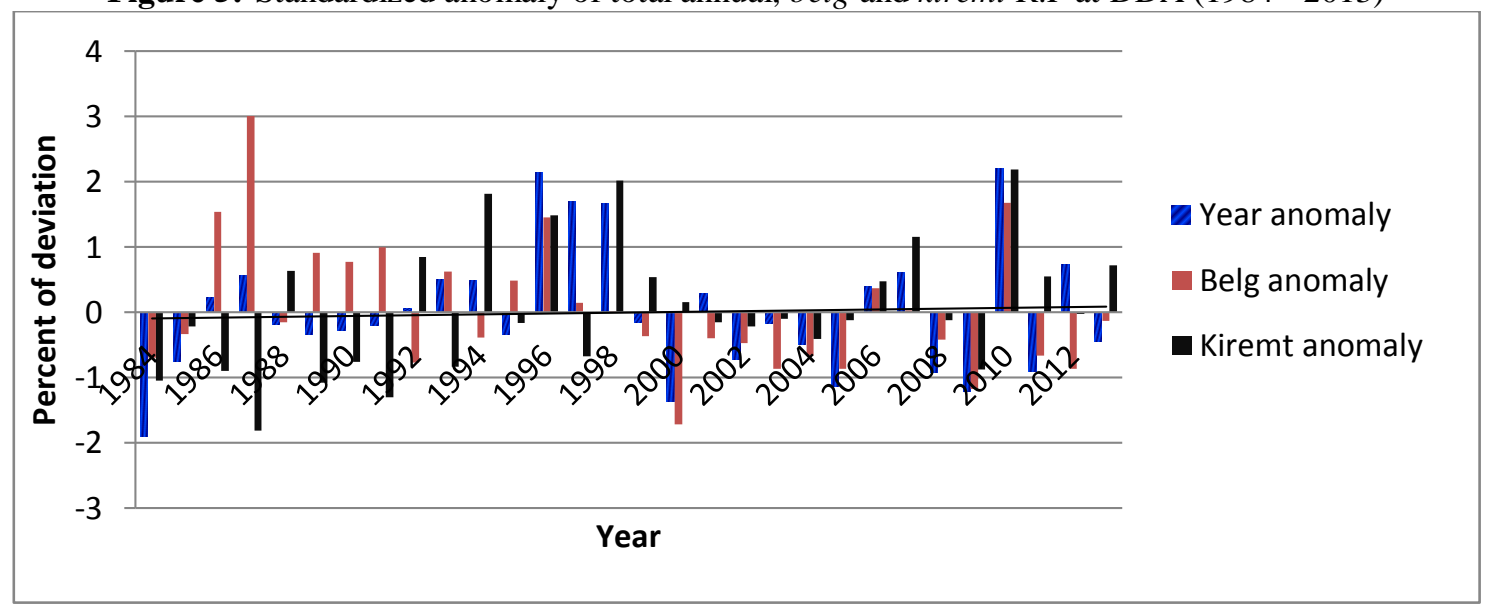

Source: NMA, 2014 (drawn by the author)

Temperature trend and variability:-

UNDP (2009) reported that, the mean annual temperature of Ethiopia has shown an increasing trend. In addition to this, according to national meteorology agency of Ethiopia (NMA, 2007) the average annual maximum temperature in the country has increased by $0.1^{\circ} \mathrm{C}$ per decade. And also the average annual minimum temperature of the country has increased by $0.37^{\circ} \mathrm{C}$ per decade. As it is shown in figures 6 and 7 both maximum and minimum temperatures increased and there was little variability of temperature from one year to the other. The average maximum and minimum temperature was increased by $0.8{ }^{\circ} \mathrm{c}$ (which is much higher than the country average) and $0.03{ }^{0} \mathrm{c}$, respectively, every decade from the period 1984 to 2013.

Figure 6:-Annual maximum temperature trend at DDA (1984-2013)

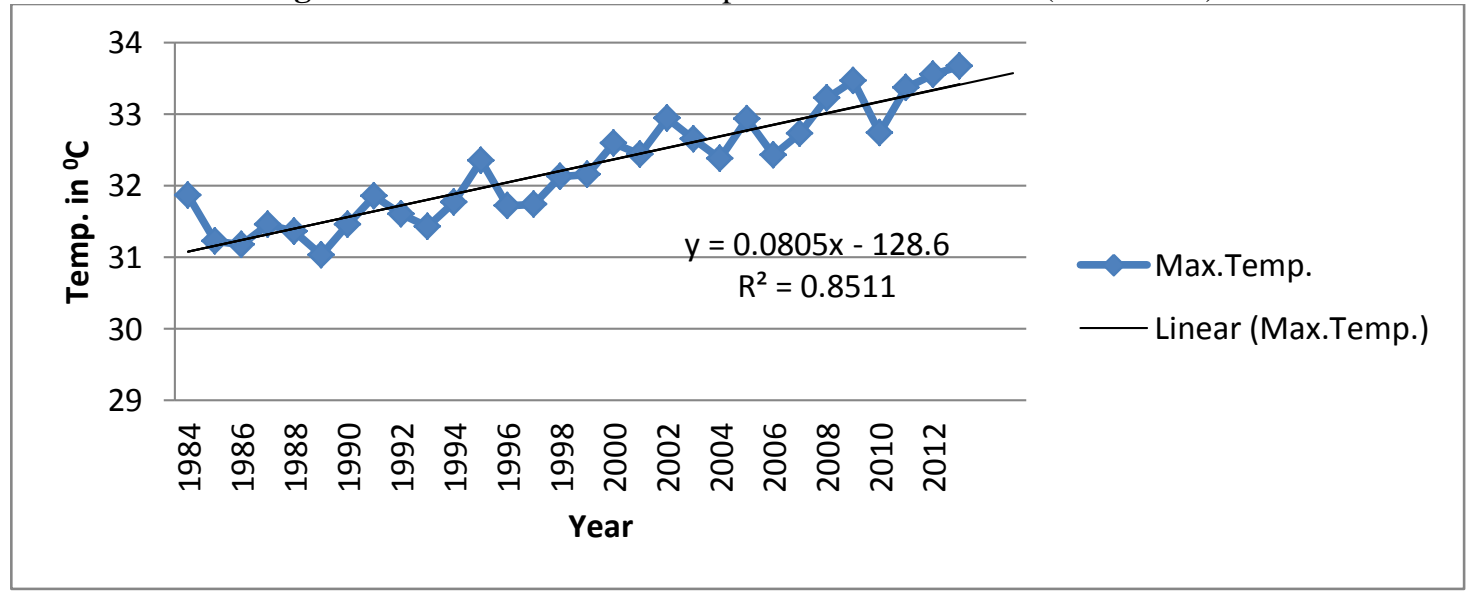

Source: NMA, 2014 (drawn by the author) 
Figure 7:-Annual minimum temperature trend at DDA (1984-2013)

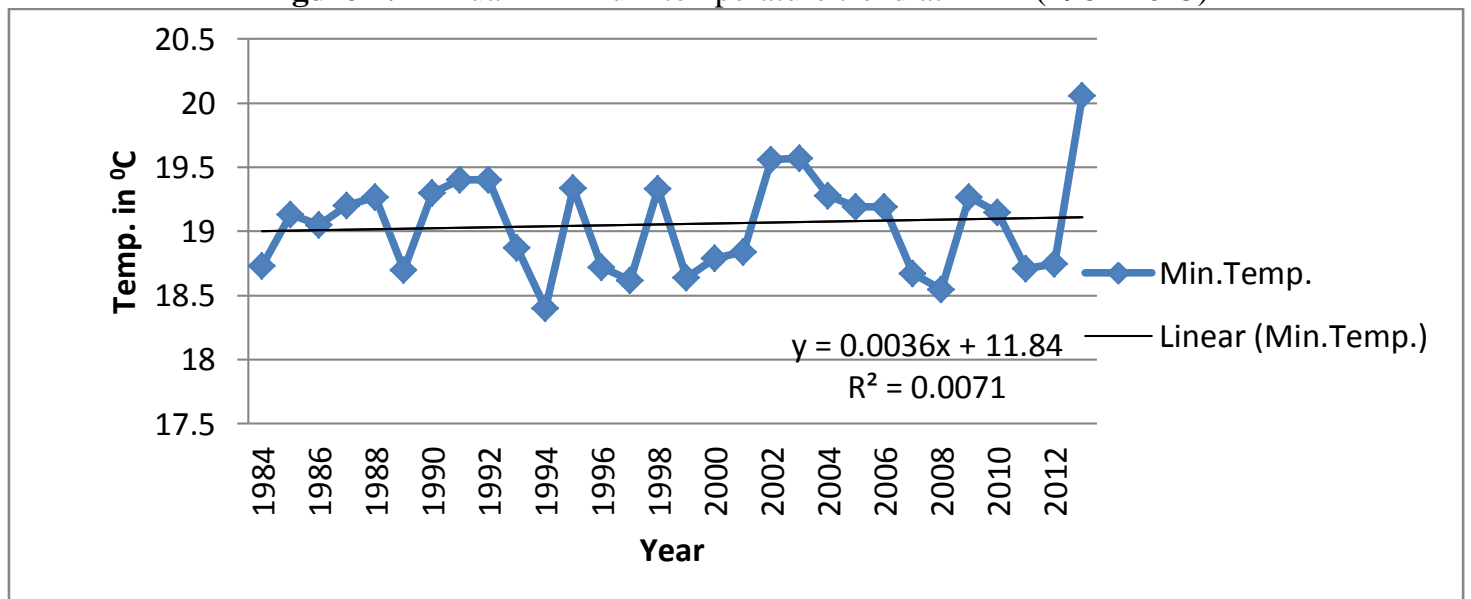

Source: NMA, 2014 (drawn by the author)

Based on analysis result of meteorological data and literature it is possible to conclude that, increased temperature and rainfall variability with frequent drought create favorable condition for pests and disease which lead to loss of agricultural production as well as water stress which aggravate loss of Livestock production and deaths.

\section{Farmers perception on climate change and variability:-}

In order to dig out locally available adaptation measure to climate change and variability it is important to have an insight of local peoples view on key elements of local climate trends of change. According the information obtained from households about the change and variability of climate at household level, all of the respondents perceived change in local climate, mainly in terms of increased temperature and decreased rainfalls. About $99 \%$ and $100 \%$ of respondents perceived increase in number of hot days and decrease in number of cold days, respectively. The majority of respondents noticed decreased in annual rainfall (71.7\% of total) and both increase in frequency of drought and decrease in annual rainfall (12.5\% of total) (Table, 3). According to FGDs conducted in both Kebeles, farmers were reported as they observe a shortening of the rainy seasons; rains start later than they used to do in the past. In addition, they said rainfall amount, frequency and distributions have changed. The problems have become more severe since the last five years. This can lead to scares or no pasture growth, increased water scarcity and depletion of resources. And they had noticed that, belg rains declined more and has become variable than rains of kiremt. In this regard, analyses of meteorological data agree with perception of farmers on climate change and variability.

These indicate that, there was lack of enough moisture for plant growth, forage for livestock and it affects crop production. As, the farmer start sowing with the coming of belg rain, moisture stress and high temperature can affect seed germination and growing performance of crops as well.

Table 3:-Farmers' perception on local climate change

\begin{tabular}{|c|c|c|c|}
\hline & Response & Frequency & Percent \\
\hline No of hot days & increased & 119 & 99.2 \\
\hline & I don't know & 1 & 0.8 \\
\hline & Total & 120 & 100 \\
\hline № of cold days & Decreased & 120 & 100 \\
\hline & Total & 120 & 100 \\
\hline Trend of rainfall & Decreased & 86 & 71.7 \\
\hline & Decreased and increased in rainy days & 15 & 12.5 \\
\hline & Increased and increased in rainy days & 9 & 7.5 \\
\hline & Increased and change times of raining & 2 & 1.7 \\
\hline & Changed in times of raining & 2 & 1.7 \\
\hline & Increased in frequency of drought & 2 & 1.7 \\
\hline & Changed in times of raining and increase in rainy & 1 & 0.8 \\
\hline
\end{tabular}




\begin{tabular}{|l|l|c|c|}
\hline & days & & \\
\cline { 2 - 4 } & Decreased and change in times of raining & 3 & 2.5 \\
\cline { 2 - 4 } & Total & 120 & 100 \\
\hline
\end{tabular}

Source: Field survey, 2014

Local indicators to climate change and variability:-

Indicators by which peoples perceived local climate change and variability includes loss of some plant and animal species, increased drought and flood frequency, change in timing of rain, decline of agricultural yield, decline of soil productivity, decreased water availability, prevalence of human and animal disease not familiar to the area, introduction of new plant species, and dry up of water resources. Out of these indicators about $23 \%$ of the respondents perceived the local climate change by observing all indicators mentioned above and about $47 \%$ of the respondents perceived the change in local climate by observing all indicators except prevalence of human and animal disease and introduction of new plant species.

Farmers perception on climate and variability impact on livelihood resources:-

Sensitivity to climate change largely depends on the main livelihood activities practiced in a community (including its dependence on livestock and rain-fed agriculture), and the specific natural, physical, financial, human and social resources needed to carry out these activities, as well as the impacts of climatic hazards on these key livelihood resources (IPCC, 2007).

Even if, protection of household and communities livelihood assets reduce vulnerability to the impacts of climate change and variability, today climate change already impose impact and will affect the globe through affecting the livelihood assets adversely by different hazards.

The main climatic hazard affecting the communities in Dire Dawa is drought. Most of the respondents (94\% of the total) ranked drought as the main climatic hazard affecting their livelihood. They also mention extreme heat, livestock diseases and flood as the second significant hazards affecting their livelihood (reported by 38.3\%, 45.8\% and $8.3 \%$ of respondents, respectively).

According to participant of FGDs drought is the major hazard experienced in the area. In addition, even though they know their action of firewood collection exacerbates the problem and affects the local climate, still they experience it. Because, according to them, firewood collection is an alternative economic activity to compensate the failure of crop and animal production.

Impact of drought on agriculture includes decreased pasture availability and water, decreased capacity of livestock to resist disease and productivity in terms of milk and meat and death of livestock. Generally, drought causes crop failure, leading to food insecurity, increased conflict over scarce resources, migration of people for search of labor work and increased school dropout.

\section{Natural capital assets:-}

According to International Institute for Sustainable Development (IISD, 2003) natural capital is natural resource stock from which resource flows useful to livelihoods are derived. The actual resources available to an individual household reflects the characteristics of the local resource base and the extent to which the household is able to gain access to these resources, which in turn reflects issues of ownership and entitlements as well as availability of technologies that makes it possible to use the resource potentials. Based on the survey data, households are observing the adverse impact of drought on natural resources such as pasture, water, vegetation e.t.c. About $95 \%$ of respondents had rated that the impact of drought on natural resource was high (See Table, 3). According to participants of FGDs drought and extreme heat events have significant negative impact on natural resources such as pasture, water sources and soil productivity and also the grazing potential of the land is going down, due to shorter rainy seasons and droughts.

\section{Physical capital assets:-}

It includes the basic infrastructure for transport, buildings, water management, energy, and communications and productive capital (tools, machines, etc.) which enables people to pursue their livelihoods. It includes both those that people own and those that they have access to (roads, irrigation systems, telephone networks, etc.) whether provided by government or the private sector (and whether free or paid for) (IISD, 2003). Most of the respondents argued that 
the impact of drought on physical resources was low and drought led to cracking of ponds, which lower its carrying capacity for the future (Table, 4$)$.

\section{Financial capital assets:-}

The result of this study shows that, financial resources of the community are depend on livestock production and its products, production of fruit and vegetables. It is directly depending on natural resources, which are sensitive to climate. To this effect, the financial resources of the communities are strongly influenced by drought and other climatic hazards. As it is shown in Table, 4 about $38 \%$ of respondents' believed that the impact of drought on financial resource was high.

\section{Human capital assets:-}

Human capital includes skills, knowledge, ability to labor and good health which is important to pursue livelihood activities. For individual households, this includes both the quantity (number of productive individuals) and the quality (what these individuals know and how hard they are able to work) of human resources. It includes knowledge and skills learned from formal education and through experience and non-formal learning (IISD, 2003). Drought affects human resource that is important to livelihoods. Decrease in crop production leads to shortage of food, reduce resistance of humans to disease, and reduce human labor productivity. Indeed, it increased migration due to drought and it enhances school dropout. These are frequently experienced in the study sites. In one or another way, the impact drought on human resources was high (Table, 4).

\section{Social capital assets:-}

Social capital is a set of social relationships upon which people draw in pursuit of their livelihood. This includes the range of contact networks, membership of groups and organizations, relationships of trust and access to wider institutions of society that are important in the actual operation of livelihood activities and that can be determining in terms of access to markets, credit, government services and many other factors of production (IISD, 2003). In the study area, drought leads to collapse of saving and credit group of communities. It decreased the capacity of communities to support poor households or who have lost assets due to different hazards. And also affect the normal interaction of people by causing conflict among people over scarce resources. According to the respondents and FGD, the impact of drought on social resource was highly recognizable (Table, 4).

Table 4:-Respondents ranking of impact of climate change and variability on livelihood assets

\begin{tabular}{|c|c|c|c|c|c|c|c|c|c|c|c|c|c|c|c|c|c|c|}
\hline \multirow{3}{*}{$\begin{array}{l}\text { Level of } \\
\text { impact }\end{array}$} & \multicolumn{18}{|c|}{ Livelihood Capital Assets } \\
\hline & \multicolumn{3}{|c|}{ Natural } & \multicolumn{4}{|c|}{ Physical } & \multicolumn{3}{|c|}{ Financial } & \multicolumn{4}{|c|}{ Human } & \multicolumn{4}{|c|}{ Social } \\
\hline & 2 & 3 & 4 & 1 & 2 & 3 & 4 & 2 & 3 & 4 & 1 & 2 & 3 & 4 & 1 & 2 & 3 & 4 \\
\hline $\begin{array}{l}\text { Legeoda } \\
\text { Gunufeta }\end{array}$ & 1 & 3 & 55 & 26 & 27 & 6 & 0 & 3 & 35 & 21 & 9 & 39 & 10 & 1 & 1 & 1 & 5 & 52 \\
\hline $\begin{array}{l}\text { Legeoda } \\
\text { Mirga }\end{array}$ & 0 & 2 & 59 & 7 & 8 & 22 & 24 & 3 & 34 & 24 & 0 & 12 & 38 & 11 & 16 & 30 & 9 & 6 \\
\hline Total & 1 & 5 & 114 & 33 & 35 & 28 & 24 & 6 & 69 & 45 & 9 & 51 & 48 & 12 & 17 & 31 & 14 & 58 \\
\hline Percent & 0.8 & 4.2 & 95 & 28 & 29 & 23 & 20 & 5 & 57.5 & 37.5 & 7.5 & 42.5 & 40 & 10 & 14 & 26 & 11.7 & 48.3 \\
\hline
\end{tabular}

Source: Field survey, 2014

Note: 1, 2, $3 \& 4$ are magnitude of hazards that show no, low, medium and high impact of hazards, respectively

Vulnerable segments of communities:-

Even though the exposure to climate change has been the same for all people in the area, its impact on livelihood of different wealth categories and social groups is not the same (IPCC, 2007). According to a report of UNDP, Women, particularly in least-developed Countries are disproportionately vulnerable because of their: Dependence on bio-fuels and other natural resources, responsibility for water procurement and household care, role in securing food and fuel predominant presence in low-technology agriculture and greater exposure to risk in crisis and severe weather events that may have been influenced or impacted by climate change (UNDP, 2009).

The participants of the FGDs also reported that women, children, elders and generally the poor were the main social groups affected by climate related hazards as they have poor adaptive capacity due to various economic and social factors. However, women particularly have several household responsibilities. Impacts of climate change and variability create additional burden on women; for instance during the condition of drought they are overburdened in 
caring for children and elder. Drought induced migration therefore causes gender and age specific experiences where women, children and elderly tend to suffer more and men migrate to Dire Dawa towns to escape the effect of drought and search for better future. And it is resulted from their poor capacity to adapt due to limited access and control of natural resources, they become more vulnerable.

\section{Household adaptation strategies to climate change:-}

Due to the impact of climate change and variability on agricultural production in particular, farmers therefore trying to develop their own strategies to cope with and adapt the impacts climate change and variability. Based on the information from FGD, local communities' have their own indigenous mechanism of adaptation like, with the problems of climate change and variability. In relation with change in rainy time early and late planting, with the increasing depletion of grasses, local communities tend to change the type of livestock to small ruminants, livestock selling and feed their animals' leaves and branches of trees. Acacia pods are also used as important sources of dry season feed for goats, camels and cattle. Due to the pressures from the invasive species (Prosopis) farmers engaged on fire wood and charcoal selling, this is especially in Legeoda Mirag kebele, and also labor migration. However, in addition to these, different adaptation measures are undertaken by farmers with the support of institutions. Such as different physical and biological soil and water conservation, agronomic and natural resource management practices. Changing cropping date (early and late planting) and use of soil and water conservation are the most commonly used methods. Additionally, Income source diversification, Shift from cattle to goats and sheep and sowing drought tolerant crops are also used as adaptation mechanism by few farmers. Moreover, they were also participating on different soil water conservation practices voluntarily for up to 30-45 days every year.

\section{Barriers to adaptation:-}

The surveyed farmers mentioned lack of money, lack of information, shortage of land, poor potential for irrigation, lack of market access, lack of credit access, lack of agricultural inputs and lack of extension service as a barrier that limit them to employ adaptation measures to adapt and cope with the negative effects of climate change and variability. All these constraints are linked with poverty.

Lack of money hinders farmers from utilizing necessary resources and technologies for adaptation. Lack of labor or money hire labor influence their capacity to adapt climate change. Shortage of land associated with high population pressure plays a great role in diminishing their potential to adapt. Poor potential for irrigation associated with lack of water resources and technologies. Lack of market access is related with poor transportation link of the area to the town nearby. Lack of credit access and agricultural inputs are highly associated with lack of institutional support. Lack of information to adaptation could be associated with various factors including lack of institutional support and research related with climate change and adaptation.

\section{Conclusion:-}

Most of the respondents perceive long-term change and variability in local climate, Such as decreased in amount of annual rainfall, shortening of rainy season, increased in frequency of drought, increased in number of hot days and decreased in number of cold days. And there was also seasonal variability in pattern and distribution of rainfall. This also confirmed by metrological data findings.

The result of meteorological data shows, there was inter-annual variability of annual rainfall and it has an increased trend. Similarly with the annual rainfall there was also inter-annual variability in the amount of belg and kiremt rainfall. Accordingly, both belg and kiremt rain shows decreasing and increasing trend. In addition to these, the average maximum and minimum temperature shows increasing trend. Due to increased temperature and erratic rainfall, the area become porn to drought and experienced a number of drought years, most of them were occurred after the year 2000 G.C.

The communities have been facing different impacts of climate change and variability, but today the impacts have become more serious. Drought is the major climatic hazard occurred in the area. And it affects the key livelihood assets (natural, physical, financial, human and social assets) on which the communities depend on it for their survival. Drought is a common phenomenon in the study area; it has become more frequent and intense in recent years, its reoccurrence interval has become shorter. This result, crop failure, decreased availability of pasture and water, decreased capacity of livestock to resist diseases and declined livestock productivity. And also it causes conflict over scares resource, school dropout and migration. Extreme heat, livestock diseases and Flood are also the main climatic hazards occurred in the study area next to drought. Women, children and elders are most affected by 
impacts of climate change and variability hazards. Mainly female children and women carry out the routine household activities. The hazards created additional burden and make them more vulnerable.

In order to overcome the impact of climate change and variability hazards, the local communities have applied different coping and adaptation strategies. Some of them are selling assets, fire wood selling, shifting planting date, employing soil and water conservation techniques, shifting from cattle to small ruminants, diversifying their income source, growing drought tolerant crops, labor migration, zero grazing, afforestation, feeding leaves of trees for their livestock and soon.

\section{Recommendation:-}

Finally, on the bases of the researchh findings, the following recommendations are forwarded.

In order to increase households adaptive capacity, improving their knowledge and skills through training, supporting them financially (credit) to increase their involvement in small scale irrigation and water harvesting, improved agricultural inputs should be disseminated timely in order to increase their income from crop and livestock production and improving transport link to increase their access to input and output market should be necessary.

Due to the availability of different micro climate in the area and to improve the coverage and quality of climatic data, local meteorology station should be established at least at woreda level. And it is important for monitoring climate data, developing climate forecasts and early warning for climatic hazards as early as possible.

Moreover, formulating effective and efficient planned and anticipatory adaptation strategy, which is depend on indigenous practices of the community. Therefore, before planning and implementing any interventions, a proper assessment of locally available adaptation options and coping strategies should be considered so as to insure its sustainability are the major points to be concerned in the way forward.

\section{Acknowledgment:-}

I would like to thank Dire Dawa Administration agriculture and rural development offices, National Meteorology Service Agency (NMSA) for providing me with meteorological and other relevant data.

\section{Reference:-}

1. Abebe Tadege (2007). Climate change National Adaptation Program of Action (NAPA) of Ethiopia. Addis Ababa, Ethiopia.

2. Assefa Admassie, Berhanu Adenew and Abebe Tadege (2008). Perceptions of stakeholders' on climate change and adaptation strategies in Ethiopia, EEA Research Report.

3. CSA (Central Statistics Authority), 2008. FDRE CSA Agricultural sample survey: report on area and production of Belg season crops for Private peasant holding, Addis Ababa.

4. DDA DPFSO (Dire Dawa Administration Disaster preparedness and food security office), 2012. An assessment report of pre and post-harvest production of 2012/2013, Dire Dawa.

5. DDAEPA (Dire Dawa Administration Environmental Protection Authority), 2011. Dire Dawa Administration Program of Adaptation to Climate Change.

6. IDS (Institute of Development Studies), 2008. Economic Impacts of Climate Change in Ethiopia.

7. IISD (International Institute for Sustainable Development), 2003. Livelihoods and climate change, International Union for Conservation of Nature and Natural Resources and Stockholm Environment Institute.

8. IPCC (Intergovernmental Panel on Climate Change), 2001. Impacts, adaptation, and vulnerability. Contribution of working group II to the third assessment report of the Intergovernmental Panel on Climate Change. Cambridge University Press, Cambridge, UK.

9. IPCC (Intergovernmental Panel on Climate Change), 2007. Impacts, adaptation and vulnerability. Contribution of working group II to the fourth assessment report of the Intergovernmental Panel on Climate Change, Cambridge University Press, Cambridge, UK.

10. Kandji S., Louis V. and Jens M. (2006). Climate change and variability in the sahel region: Impacts andAdaptation Strategies in the Agricultural Sector. Report for UNEP \& ICRAF.

11. Mendelsohn R., Dinar A. and Dalfelt A. (2000). Climate change impacts on African Agriculture. Preliminary analysis prepared for the World Bank, Washington, District of Columbia. 
12. Mesfin Duguma, 2006. Farmers' perception on soil erosion and decision on land management in Assosa Woreda, Ethiopia. Harmaya University, Ethiopia.

13. Mideksa K. (2010). Economic and distributional impacts of climate change: the case of Ethiopia. Global environ. Change, doi:10.1016/j.gloenvcha.2009.11.007.

14. NMA (National Meteorological Agency), 2007. Climate change: National Adaptation Program of Action (NAPA) of Ethiopia. Ministry of Water Resource, Addis Ababa.

15. MoA (Ministry of Agriculture), 2010. Ethiopia's agriculture sector policy and investment framework.

16. Temesgen Tadesse (2007). Measuring the economic impact of climate change on Ethiopian agriculture: Ricardian approach. World Bank Policy Research Paper No. 4342. World Bank, Washington D.C.

17. UNDP (2009). Resource guide on gender and climate change, New York.

18. United Nations (2008). Situation report: Drought/Food crisis in Ethiopia $27^{\text {th }}$ June 2008.

19. USAID (2004). Breaking the cycle of food crises: famine prevention in Ethiopia.

20. World Bank (2003). Africa rainfall and temperature evaluation system. World Bank, Washington, DC. 